\title{
Palliative Care in Paediatric Oncology: an Update
}

\author{
Naveen Salins ${ }^{1} \cdot$ Sean Hughes ${ }^{2} \cdot$ Nancy Preston $^{2}$
}

Accepted: 9 November 2021 / Published online: 21 January 2022

(c) The Author(s) 2022

\begin{abstract}
Purpose of this Review The purpose of this review is to describe the evolution of palliative care in paediatric oncology, the needs of children and their families in a paediatric oncology setting, palliative care referral practices in paediatric oncology, outcomes of palliative care referral in paediatric oncology and models of palliative care in paediatric oncology.

Recent Findings Cancer constitutes 5.2\% of the palliative care needs in children. Approximately, 90\% of children with cancer lives in low and middle-income countries, constituting $84 \%$ of the global burden of childhood cancers. Children in low and middle-income countries have low cure rates and high death rates making palliative care relevant in a paediatric oncology setting. Children with cancer experience pain and physical symptoms, low mood, anxiety, and fear. They feel less resilient, experience low self-worth, and have challenges coping with the illness. The families lead very stressful lives, navigating the hospital environment, and dealing with uncertainties of the future. Palliative care referral in children with cancer improves physical symptoms, emotional support, and quality of life. It enables communication between families and health care providers. It improves end-of-life care support to children and their families and facilitates less invasive diagnostic and therapeutic interventions at the end of life. Worldwide children with cancer are infrequently referred to palliative care and referred late in the illness trajectory. Most of the children referred to palliative care receive some form of cancer-directed therapy in their last days. Children in low and low-middle income countries are less likely to access palliative care due to a lack of awareness amongst paediatric oncologists about palliative care and the reduced number of services providing palliative care. A three-tier model is proposed to provide palliative care in paediatric oncology, where most children with palliative care needs are managed by paediatric oncologists and a smaller number with complex physical and psychosocial needs are managed by paediatric palliative care specialists. There are several palliative care models in paediatric oncology practised globally. However, no one model was considered better or superior, and the choice of model depended on the need, preferences identified, and available resources.

Summary Children with cancer are sparingly referred to palliative care and referred late and oncologists and haematologists gatekeep the referral process. Knowledge on palliative care referral in paediatric oncology settings might enhance collaboration between paediatric oncology and paediatric palliative care.
\end{abstract}

Keywords Cancer $\cdot$ Oncology $\cdot$ Children $\cdot$ Paediatric $\cdot$ Palliative

This article is part of the Topical collection on Palliative Medicine

Naveen Salins

naveen.salins@manipal.edu

Sean Hughes

sean@phonecoop.coop

Nancy Preston

n.j.preston@lancaster.ac.uk

1 Department of Palliative Medicine and Supportive Care, Kasturba Medical College Manipal, Manipal Academy of Higher Education, Manipal, Karnataka 576104, India

2 Division of Health Research, Health Innovation One, Lancaster University, Sir John Fisher Drive, Lancaster LA1 4AT, UK

\section{Introduction}

Children's palliative care provides active, holistic care for children and young people with life-limiting illnesses [1]. It is provided from the point of a child's diagnosis, throughout the child's life, death, and bereavement. It encompasses all elements of quality of life; physical, emotional, social, and spiritual. It focuses on enhancing a child's quality of life and providing support to the family. The scope of palliative care provision is not limited to symptom management, but includes respite services, end of life care, and bereavement support [1]. Palliative care is provided regardless of whether 
or not a child receives treatment directed at the disease and should be incorporated alongside active disease-directed therapies [2]. Multidisciplinary palliative care support is individualised according to the child's needs. The extent of support from the palliative care team might vary depending upon the child's illness and response to therapy [1]. It is essential to provide children's palliative care in tertiary, secondary hospitals and the community to ensure adequate and uninterrupted care [2].

Compared to the 1998 World Health Organisation (WHO) definition of paediatric palliative care [2], the 2013 definition provided an augmented scope [1]. It included aspects relating to spiritual elements of care and enhancing the quality of life [3]. Furthermore, it also incorporated respite care, bereavement support and personalising the care approach [3]. Some oncologists felt that the paediatric palliative care definition is unclear and without distinct boundaries due to the overlap in care components between two disciplines [4]. Although most oncologists comprehended the modern definition of palliative care, integrating palliative care into paediatric oncology practice was often less well understood [5•].

Globally, cancer constitutes only $5.2 \%$ of the palliative care needs in children [6]. The lower percentage is attributed to the uncommonness of childhood cancers and the success of currently available treatment [7]. Excellent outcomes in childhood cancer have diminished palliative care's relevance in paediatric oncology $[8,9]$. However, palliative care continues to be identified with oncology where it originated and inequitable referral of children with non-cancer conditions to palliative care services [10]. It is estimated that $90 \%$ of children with cancer live in low and middle-income countries, constituting $84 \%$ of the global burden of childhood cancers [11]. Moreover, palliative care in paediatric oncology remains relevant in low and low-middle income countries due to low cure rates and high death rates [12, 13]. In this review, we discuss the evolution of palliative care in paediatric oncology, the needs of children and their families in a paediatric oncology setting, palliative care referral practices in paediatric oncology, outcomes of palliative care referral in paediatric oncology, and models of palliative care in paediatric oncology.

\section{Evolution of Palliative Care in Paediatric Oncology}

In 1997, The Association for Children's Palliative Care (ACT) and the Royal College of Paediatrics and Child Health (RCPCH) jointly categorised chronic and life-limiting conditions $[14,15]$. The categorisation of conditions is provided in Table 1. Childhood cancers were categorised as ACT 1 [14]. All these conditions were suitable for palliative care, but the nature and level of palliative care involvement varied significantly from one category to another [15].

The first guidelines on integrated palliative care in paediatric oncology were published in 2013 [16]. Guidelines mandated creating a specialist interdisciplinary team that can provide collaborative multi-modal care across all settings. The purpose was to provide support to children and their families whilst ensuring the child's quality of life and safety. It advocated for child and family participation during communication and decision making. Moreover, guidelines emphasised the understanding of ethical aspects of care during a child's end of life experience [16]. Another integrated palliative care model in paediatric oncology highlighted the provision of palliative care concurrently regardless of the disease status and improving palliative care familiarity by

Table 1 Categorisation of chronic and life-limiting conditions in paediatrics

\begin{tabular}{|c|c|c|c|}
\hline $\begin{array}{l}\text { ACT } \\
\text { cat- } \\
\text { egory }\end{array}$ & Description & Key characteristics & Examples \\
\hline 1 & $\begin{array}{l}\text { Curative treatment may be feasible but can fail. } \\
\text { Palliative care may be necessary during phases } \\
\text { of prognostic uncertainty and when treatment } \\
\text { fails }\end{array}$ & Possibility of cure & $\begin{array}{l}\text { Cancer and certain cardiac } \\
\text { conditions }\end{array}$ \\
\hline 2 & $\begin{array}{l}\text { A long duration of intensive treatment needed } \\
\text { to prolong life, but premature death is still } \\
\text { possible }\end{array}$ & $\begin{array}{l}\text { Prolonged course with predominantly normal } \\
\text { phase, waxing, and waning of health conditions }\end{array}$ & $\begin{array}{l}\text { Cystic fibrosis, muscular dys- } \\
\text { trophy, and HIV/AIDS with } \\
\text { antiretroviral treatment }\end{array}$ \\
\hline 3 & $\begin{array}{l}\text { Progressive conditions without curative treat- } \\
\text { ment options, in which treatment is exclusively } \\
\text { palliative }\end{array}$ & Prolonged course with progressive worsening & $\begin{array}{l}\text { Batten's disease, mucopolysac- } \\
\text { charidosis, and HIV/AIDS } \\
\text { without antiretroviral treatment }\end{array}$ \\
\hline 4 & $\begin{array}{l}\text { Conditions with severe neurological disability, } \\
\text { which may cause weakness and susceptibility } \\
\text { to health complications and may deteriorate } \\
\text { unpredictably but are not considered progres- } \\
\text { sive }\end{array}$ & $\begin{array}{l}\text { Non-progressive condition with an unpredictable } \\
\text { course }\end{array}$ & Cerebral palsy \\
\hline
\end{tabular}


building relationships between palliative care specialists and paediatric oncologists [17]. Furthermore, palliative care was proposed as a standard of care in paediatric oncology [18], and the American Society of Clinical Oncology (ASCO) in one of its publications recommended the integration of palliative care in the routine care of children, adolescents, and young adults with cancer [19].

\section{Needs of Children and their Families in a Paediatric Oncology Setting}

Pain is one of the common symptoms experienced by a child with cancer [20]. Pain is not just limited to the palliative phase [21-23]; children receiving active treatment also experience procedural pain whilst establishing a diagnosis and during cancer treatment [24, 25]. Pain is more often seen in children with solid tumours than haematological malignancies [26, 27]. Both children and their families have voiced inadequate pain management as a concern [28, 29], and felt that this gap needs to be addressed [30].

Breathlessness, nausea, fatigue, and loss of appetite are common non-pain symptoms seen in children with cancer during treatment and palliative phases [31,32]. Children also had symptoms like fever, mouth ulcers, diarrhoea, headache, and neuropathy due to acute and long-term chemotherapy adverse effects [33]. They experienced low mood, worry, anxiety, fear, irritability, and anger [34, 35]. They also had difficulties conveying their feelings and often reported poor concentration, low energy, and lack of motivation [23, 32]. They felt less resilient, experienced low self-worth, and had challenges coping with illness [36]. They also reported body image issues that caught their peers' attention, and they experienced peer isolation and bullying [37]. Prolonged hospitalisation meant disruption to school and play and a transformation of the home-school-play cycle to the homehospital cycle, which children found very distressing [38].

Children with cancer were often not informed about their diagnosis by their health care providers, and the older children, who were able to comprehend, felt a need to know [39, 40]. Adolescents with cancer felt that the illness destroyed the hope of a promising future [41]. Moreover, fear of death amongst children was seldom addressed [42]. Although some could reconcile and find meaning in life situations, others were not at peace and had a sense of loss [43].

The parents of children with cancer found it challenging to manage emotional issues like feelings of isolation and behavioural changes of their children [44]. The families led very stressful lives, navigating the hospital environment and dealing with uncertainties of the future whilst ensuring timely treatment of their child [36, 45, 46]. Families also needed financial help, practical tips on managing the child at home, and supporting other children [47, 48]. Moreover, financial difficulties contributed to psychological distress amongst parents [49].

Families felt that continuous communication between parents, family caregivers, and health care providers is crucial during a child's end of life care to facilitate decision-making [50-52] and integrated palliative care [53•]. Learning about a child's diagnosis was highly distressing for parents [54•]. Commonly, they did not receive clear and honest communication about their child's illness, and they emphasised the need to know about their child's prognosis and what to expect $[51,55]$. Families often appreciated sensitive communication that preserved hope rather than blunt truth-telling [56]. There was often a gap between the child's understanding and experience of illness and parental perception of what the child knows [57•]. This gap led to barriers in communication within families.

In a terminal care setting, families often felt unprepared to deal with their child's death $[52,58]$. They were either surprised by the child dying quickly or anxious about the long wait for the child's death [59]. They found it difficult to let go of the child's cancer treatment, and transition to palliative care and adaptation to the new care provider was challenging [60, 61]. Families perceived involving palliative care as letting go of their child's treatment and experienced feelings of abandonment [58, 61, 62].

In hindsight, some families regretted providing acute hospital-based care for their child during the terminal phase of illness and regretted their child receiving cancer-directed therapy at the end of life [50,63]. Most parents experienced anticipatory grief and guilt, and poorly controlled symptoms at the child's end of life was a common trigger for complex bereavement amongst the parents [50, 64-66]. Furthermore, parents found grief isolating due to a lack of societal understanding of their grief [67]. Although all studies supporting the views on society and grief in the narrative review were from North America [67], similar observations were made in an Indian study where grief associated with perinatal loss and a child's death was inadequately recognised by the families, healthcare providers, and the society [68].

\section{Palliative Care Referral Practices in Paediatric Oncology}

Globally, children with cancer were infrequently referred to palliative care and referred late in the illness trajectory [69-74]. The median time gap from cancer diagnosis to palliative care referral was eighteen months [75]. Only $16 \%$ was referred at the initial diagnosis, and 58\% of the referrals happened after a cancer relapse [70]. Moreover, in most studies, palliative care referral occurred only in the last days of their lives $[31,70,72,76]$. In a recent systematic review, internationally, the median duration between specialist palliative 
care referral and death was 19 days [77•]. However, this was not a paediatric specific review.

Similar to adult cancer setting, children with haematological malignancies were referred to palliative care less often than children with solid tumours [31, 78-81] and opportunities for palliative care referral and integration in these settings were often missed [82•]. Many children referred to palliative care received some form of chemotherapy in their last days $[31,72,73,80]$. Amongst the children referred, reasons underpinning the referral, goals of care discussions, and the decision-making process for referral were seldom documented [71, 78, 83]. Presence of symptoms, psychosocial needs, and poor prognosis commonly activated a palliative care referral $[84 \bullet \bullet, 85 \bullet \bullet$. However, not addressing uncertainties and avoiding conversations about death and dying often hindered referral in a paediatric oncology setting [86••]. Non-referral and delayed referral often led to invasive medical interventions at the end of life [73, 79] and increased in-hospital deaths [72, 73, 79, 87]. There was a mixed view of trial participation and palliative care referral with enrolment in one clinical trial resulting in deferred palliative care referral [88] but in another study in a clinical trial setting this did not happen [89].

Children in low and low-middle income countries are less likely to access palliative care due to a lack of awareness amongst paediatric oncologists about palliative care and the reduced number of services providing palliative care [90•]. Two Indian studies showed that $86 \%$ of children with cancer received chemotherapy during the last month of their life, and $78 \%$ was referred after cancer-directed therapy was completed, which hindered palliative care access [91, 92]. These studies mirrored palliative care referral practices in the Indian adult cancer settings [93-97]. Non-referral and late referral to palliative care in paediatric oncology in Malaysia, Nigeria, and Morocco led to poorly controlled symptoms, caregiver distress, and most of the children dying within a few weeks of palliative care referral [35, 98-100]. Moreover, availability and access to paediatric palliative care in these settings were proportional to the country's health spending $[101,102 \bullet, 103 \bullet \bullet]$. Low and low-middle income countries had limited access to opioids, lack of interdisciplinary care, and families were less empowered to participate in decision-making [101, 103••]. Lack of palliative care funding, advocacy and leadership were the other factors hindering the capacity to provide paediatric palliative care [104-106]. Similar observations were made in a narrative review that identified lack of opioids and fear of opioids, lack of specialist paediatric palliative care education, lack of a national and institutional palliative care policy, lack of awareness about palliative care needs, and lack of integration of palliative care in health systems as the key barriers hindering palliative care development in low and low-middle income countries [107]. The Paediatric palliative screening scale $(\mathrm{PaPaS})$ was found to be an effective screening tool to assess palliative care needs of children and their families and the $\mathrm{PaPaS}$ score enabled clinicians to initiate timely referrals [108].

\section{Outcomes of Palliative Care Referral in Paediatric Oncology}

Although improvement in children and their families' quality of life is the desired outcome, there are no ideal measures that accurately reflect these outcomes of palliative care referral in paediatric oncology [109]. Improvements in the domains of quality of life have to be contextualised to a specific illness and patient population [109]. Betterment of the child's quality of life is an essential factor motivating families to access palliative care [110]. Empirical studies have shown improvements in quality of life from palliative care referral in paediatric oncology [111-114]. However, these benefits were limited to physical and emotional domains of quality of life [113].

Symptom management is a critical component of the physical domain of quality of life. Studies have shown symptom assessment $[115,116]$ and symptom management benefit from paediatric palliative care referral $[74,75,112$, 115-121]. However, pain management benefit was better appreciated by children and families than the management of other symptoms $[74,75,118,121]$. Furthermore, some oncologists felt that palliative care could enable treatment completion by managing pain and symptoms whilst the child is receiving cancer-directed therapy. Two systematic reviews substantiated the above findings [122, 123].

Referral to palliative care facilitated emotional support to children and their families [74, 118, 124-127]. Emotional support to families extended beyond the child's death into the bereavement phase [126, 127]. Support from palliative care enabled families to have realistic hope. Moreover, children and families engaged in fun activities and experienced events that added meaning to their lives [124, 125].

Referral to palliative care in paediatric cancer settings improved communication between families and health care providers [74, 75, 119, 125-132]. Involvement of the palliative care team enabled early assessment [133]; facilitated initiation of family meetings during the child's clinical deterioration [128] and assisted oncologists in prognostic discussions [74]. Palliative care teams participated in family communications during the discussion of end-of-life care $[75,129,130]$, and helped paediatric oncologists to navigate critical communications surrounding the child's end of life [130]. Palliative care referral enabled goals of care discussion and supported the process of shared decision-making $[74,75,125,131,132,134,135]$. Paediatric oncologists acknowledged the complexities of shared decision-making and appreciated the support they received from the palliative 
care team [135]. Referral facilitated documentation of the resuscitation preferences $[74,136]$ and the preferred place of care and death $[75,126,137,138]$. Palliative care involvement also facilitated advance care planning and documentation of advanced directives [139, 140].

Palliative care input bettered end-of-life care support to children and their families in a paediatric cancer setting [74, $75,111,115,120,121,124,126,132,137,139-143]$. It facilitated less invasive diagnostic and therapeutic interventions at the end of life [115, 132, 137, 142], and children receiving palliative care input were less often resuscitated $[74,75]$. Children had fewer elective and emergency hospital admissions [139, 141], and they had shorter hospital stays $[111,142]$. There were fewer intensive care admissions [ 74 , $121,140]$ and more home deaths $[70,71,121,124]$. Referral to palliative care reduced overall health care resource utilisation, maintained care continuity at the end of life [120,143], and facilitated access to integrative therapies during the end of life phase [115]. However, a systematic review reported conflicting evidence on palliative care collaboration benefits on hospital admissions at the end of life and resuscitation at the time of death [144].

The families of children with cancer appreciated the healthcare system's support beyond usual clinical management $[47,48]$. They valued the support they got in terms of managing finances and assistance to manage the child's needs at home [48]. Palliative care referral improved family satisfaction of care [114, 119, 127]. Involving a palliative care team facilitated discharge planning, hospice utilisation, and home-based care $[75,145]$. Children receiving homebased care received uninterrupted care [146, 147]. The families valued the palliative care team as a reliable and cost-effective source of support [147, 148].

\section{Models of Palliative Care in Paediatric Oncology}

In 2016, a three-tier model was proposed by Kaye and the team to provide palliative care in paediatric oncology [149], as represented in Table 2. It was developed from the earlier proposed integrative paediatric palliative oncology models [150-154]. In this approach, a vast majority of children with palliative care needs are seen by tier 1 services, whereas a smaller number with complex physical and psychosocial needs are seen by tier 3 services [149].

There are five palliative care models in paediatric oncology practised in various hospitals of the USA [155•] (Table 3). No model was considered better or superior, and the choice of model depended on the need, preferences identified, and available resources. A centre with minimal resources may choose a trigger-based or a consultative model, whereas a centre with better resources may prefer a disease-specific embedded mode [155•]. Embedded paediatric palliative oncology models demonstrated a higher number of children accessing palliative care, longer stay with the palliative care service before death, and fewer days in the hospital during the last three months of their lives [156•, 157•]. Moreover, the embedded model facilitated better acceptance of paediatric palliative care by the paediatric oncology providers [158•], and improved palliative care education of paediatric oncology residents [159]. Furthermore, these models may be contextual to the US setting, and their transferability to other country settings, with scarce palliative care resources, might be challenging. Apart from these models, an Italian study showed that a virtual paediatric palliative care support network situated outside the hospital could partially substitute the lack of in-hospital palliative care services [160].

\section{Conclusion}

In summary, paediatric palliative care is the multidisciplinary holistic care of the child and the family throughout the illness continuum. Children with cancer experience physical symptoms and reduced quality of life. Families are often unprepared to deal with the loss and find it challenging to cope with emotional issues. Palliative care referral improves quality of life, confers symptom management benefit, provides emotional support, enhances end of life care experience, and supports children and their families' needs. Children with cancer were sparingly referred to palliative care and referred late and oncologists and haematologists gatekeep the referral process. Knowledge on palliative care referral in paediatric oncology settings has the potential to provide some strategies to enhance

Table 2 Three-tier model of palliative care in paediatric oncology

\begin{tabular}{lc}
\hline Tier & Description \\
\hline $\begin{array}{l}\text { Tier } 1 \\
\text { Specialist palliative Care }\end{array}$ & $\begin{array}{c}\text { A team of specialist paediatric palliative care providers available for managing complex symptoms and psychosocial } \\
\text { needs } \\
\text { Tier } 2\end{array}$ \\
$\begin{array}{l}\text { Presence of a consultation-liaison service, and there are triggers for palliative care referral. When the child satisfies } \\
\text { the referral criteria, a consultation is triggered }\end{array}$ \\
$\begin{array}{l}\text { Tier } 3 \\
\text { Palliative approach }\end{array}$ & A palliative approach where all the oncologists, oncology trainees, and oncology nurses have basic training in pallia- \\
\end{tabular}


Table 3 Models of palliative care clinics in paediatric oncology

\begin{tabular}{|c|c|c|}
\hline Model & Description & Site practiced \\
\hline The floating clinic & $\begin{array}{l}\text { A paediatric advanced care team (PACT) } \\
\text { comprised of paediatric palliative care } \\
\text { physician, paediatric palliative care nurse } \\
\text { practitioners, and social workers called as a } \\
\text { "floating unit" moves along with the child in } \\
\text { the hospital and consults them during out- } \\
\text { patient oncology visits, hospital admission, } \\
\text { day-care chemotherapy, and transplantation }\end{array}$ & Boston's Children's Hospital, Boston \\
\hline The disease-specific embedded clinic & $\begin{array}{l}\text { A team of paediatric palliative care physicians } \\
\text { and paediatric palliative care nurse prac- } \\
\text { titioners are situated in a disease-specific } \\
\text { clinic like leukaemia clinic, neuro-oncology } \\
\text { clinic, or solid tumour clinic and they } \\
\text { closely work with these disease-specific } \\
\text { units and provide palliative care across all } \\
\text { settings }\end{array}$ & St. Jude's Children Research Hospital, Memphis \\
\hline $\begin{array}{l}\text { Trigger-based Clinic embedded in the oncol- } \\
\text { ogy space }\end{array}$ & $\begin{array}{l}\text { The team is comprised of paediatric palliative } \\
\text { care physician, paediatric palliative care } \\
\text { nurse, and social workers. A disease-specific } \\
\text { criterion is created for palliative care refer- } \\
\text { ral. When the child meets the referral crite- } \\
\text { ria, the oncology team initiates the referral } \\
\text { process and seen by the paediatric palliative } \\
\text { care team in the oncology clinic }\end{array}$ & Randy Children's Hospital, San Diego \\
\hline $\begin{array}{l}\text { Consultation based clinic in the oncology } \\
\text { space }\end{array}$ & $\begin{array}{l}\text { A need-based referral initiated by oncologists } \\
\text { to paediatric palliative care. There are no } \\
\text { set referral criteria in this model, and the } \\
\text { palliative care specialist is usually a dual } \\
\text { board-certified clinician in both palliative } \\
\text { care and oncology. The oncology team and } \\
\text { the palliative care team see the child con- } \\
\text { currently in the same clinic, and the child } \\
\text { receives joint advice }\end{array}$ & $\begin{array}{l}\text { Alfac Cancer and Blood Disorders centre, } \\
\text { Atlanta }\end{array}$ \\
\hline Telehealth clinic & $\begin{array}{l}\text { Providing access to children and their families } \\
\text { in a remote or rural setting beyond the } \\
\text { geographic catchment of the regular pal- } \\
\text { liative care services. The clinic is operated } \\
\text { by a team of palliative care providers, who } \\
\text { provide telephonic, and video-calling based } \\
\text { consultations }\end{array}$ & Children's Hospital and Medical Centre, Omaha \\
\hline
\end{tabular}

collaboration between paediatric oncology and paediatric palliative care.

Author Contribution The manuscript has been read and approved by all the authors, and all the authors meet requirements for authorship.

Funding Open access funding provided by Manipal Academy of Higher Education, Manipal.

\section{Declarations}

Conflict of Interest Naveen Salins, Sean Hughes, and Nancy Preston declare no conflict interest.

Open Access This article is licensed under a Creative Commons Attribution 4.0 International License, which permits use, sharing, adaptation, distribution and reproduction in any medium or format, as long as you give appropriate credit to the original author(s) and the source, provide a link to the Creative Commons licence, and indicate if changes were made. The images or other third party material in this article are included in the article's Creative Commons licence, unless indicated 
otherwise in a credit line to the material. If material is not included in the article's Creative Commons licence and your intended use is not permitted by statutory regulation or exceeds the permitted use, you will need to obtain permission directly from the copyright holder. To view a copy of this licence, visit http://creativecommons.org/licenses/by/4.0/.

\section{References}

Papers of particular interest, published recently, have been highlighted as:

- Of importance

$\bullet \bullet$ Of major importance

1. Together for Short Lives. Together for short lives definition of children's palliative care. Together for Short Lives Accessed 5th February 2021 https://www.togetherforshortlives.org.uk/chang ing-lives/supporting-care-professionals/introduction-childrenspalliative-care/

2. WHO. WHO Definition of Palliative Care. Accessed 06 September 2020. https://www.who.int/cancer/palliative/definition/en/

3. Bergstraesser E. Pediatric palliative care: a reflection on terminology. Palliat Care. 2013;7:31-6. https://doi.org/10.4137/ PCRT.S12800.

4. Laronne A, Granek L, Wiener L, Feder-Bubis P, Golan H. Oncologist conceptualizations of pediatric palliative care: challenges and definitions. Support Care Cancer. 2021. https://doi. org/10.1007/s00520-020-05959-z.

5. Cuviello A, Raisanen JC, Donohue PK, Wiener L, Boss RD. Defining the boundaries of palliative care in pediatric oncology. Article. J Pain Symptom Manag. 2020;59(5):1033-1042. e1. https://doi.org/10.1016/j.jpainsymman.2019.11.022. (This survey study conducted among paediatric oncologists of United States showed that integration of palliative care into paediatric oncology was often less understood among the paediatric oncologists.)

6. Knaul. F, Radbruch. L, Connor. S, et al. How many adults and children are in need of palliative care worldwide? In: Connor SR, ed. Global Atlas of Palliative Care. 2nd ed. Worldwide Hospice Palliative Care Alliance; 2020.

7. Siden H. Pediatric palliative care for children with progressive non-malignant diseases. Children (Basel). 2018;5(2):28. https:// doi.org/10.3390/children5020028.

8. Cheng BT, Rost M, De Clercq E, Arnold L, Elger BS, Wangmo T. Palliative care initiation in pediatric oncology patients: a systematic review. Cancer Med. 2019;8(1):3-12. https://doi.org/10. 1002/cam4.1907.

9. O'Leary M, Krailo M, Anderson JR, Reaman GH, Children's OG. Progress in childhood cancer: 50 years of research collaboration, a report from the Children's Oncology Group. Semin Oncol. 2008;35(5):484-93. https://doi.org/10.1053/j.semin oncol.2008.07.008.

10. Chen M-L. Inequity of palliative care for non-cancer patients. J Nurs Res. 2019;27(2):1-2. https://doi.org/10.1097/jnr.00000 00000000324

11. Magrath I, Steliarova-Foucher E, Epelman S, et al. Paediatric cancer in low-income and middle-income countries. Lancet Oncol. 2013;14(3):e104-16. https://doi.org/10.1016/S14702045(13)70008-1.

12. Arora RS, Arora B. Acute leukemia in children: a review of the current Indian data. South Asian J Cancer. 2016;5(3):155-60. https://doi.org/10.4103/2278-330X.187591.

13. Gupta S, Morris SK, Suraweera W, Aleksandrowicz L, Dikshit $\mathrm{R}$, Jha P. Childhood cancer mortality in India: direct estimates from a nationally representative survey of childhood deaths. J Glob Oncol. 2016;2(6):403. https://doi.org/10.1200/JGO.2015. 000935.

14. Association for Children with Life-threatening or Terminal Conditions and their Families, Baum D. A guide to the development of children's palliative care services. Association for Children with Life-threatening or Terminal Conditions and their Families; 1997.

15. Wood F, Simpson S, Barnes E, Hain R. Disease trajectories and $\mathrm{ACT} / \mathrm{RCPCH}$ categories in paediatric palliative care. Palliat Med. 2010;24(8):796-806.

16. Section on Hospice Palliative Medicine and Committee on Hospital Care. Pediatric palliative care and hospice care commitments, guidelines, and recommendations. Pediatrics. 2013;132(5):966-972. https://doi.org/10.1542/peds.2013-2731

17. Waldman E, Wolfe J. Palliative care for children with cancer. Nat Rev Clin Oncol. 2013;10(2):100-7. https://doi.org/10.1038/nrcli nonc.2012.238.

18. Weaver MS, Heinze KE, Kelly KP, et al. Palliative care as a standard of care in pediatric cncology. Pediatr Blood Cancer. 2015;62(S5):S829-33. https://doi.org/10.1002/pbc.25695.

19. Snaman J, McCarthy S, Wiener L, Wolfe J. Pediatric palliative care in oncology. J Clin Oncol. 2020;38(9):954-62. https://doi. org/10.1200/JCO.18.02331.

20. Contro N, Larson J, Scofield S, Sourkes B, Cohen H. Family perspectives on the quality of pediatric palliative care. Arch Pediatr Adolesc Med. 2002;156(1):14-9. https://doi.org/10.1001/archp edi.156.1.14.

21. Drake R, Frost J, Collins JJ. The symptoms of dying children. J Pain Symptom Manage. 2003;26(1):594-603. https://doi.org/ 10.1016/S0885-3924(03)00202-1.

22. Hendricks-Ferguson V. Physical symptoms of children receiving pediatric hospice care at home during the last week of life. Oncol Nurs Forum. 2008;35(6):E108-15. https://doi.org/10.1188/08. onf.e108-e115.

23. Hongo T, Watanabe C, Okada S, et al. Analysis of the circumstances at the end of life in children with cancer: symptoms, suffering and acceptance. Pediatr Int. 2003;45(1):60-4.

24. Darcy L, Knutsson S, Huus K, Enskar K. The everyday life of the young child shortly after receiving a cancer diagnosis, from both children's and parent's perspectives. Cancer Nurs. 2014;37(6):445-56.

25. Wise BV. In their own words: the lived experience of pediatric liver transplantation. Qual Health Res. 2002;12(1):74-90. https://doi.org/10.1177/1049732302012001006.

26. Goldman A, Hewitt M, Collins GS, Childs M, Hain R. Symptoms in children/young people with progressive malignant disease: United Kingdom children's cancer study group/paediatric oncology nurses forum survey. Pediatrics. 2006;117(6):e1179-86.

27. Macartney G, VanDenKerkhof E, Harrison MB, Stacey D. Symptom experience and quality of life in pediatric brain tumor survivors: a cross-sectional study. J Pain Symptom Manage. 2014;48(5):957-67. https://doi.org/10.1016/j.jpainsymman. 2013.12.243.

28. Ljungman G, Gordh T, Sorensen S, Kreuger A. Pain in paediatric oncology: interviews with children, adolescents and their parents. Acta Paediatr. 1999;88(6):623-30. https://doi.org/10. $1080 / 08035259950169279$.

29. Pöder U, Ljungman G, von Essen L. Parents' perceptions of their children's cancer-related symptoms during treatment: a prospective, longitudinal study. J Pain Symptom Manage. 2010;40(5):661-70. https://doi.org/10.1016/j.jpainsymman. 2010.02.012.

30. Oberholzer AE, Nel E, Myburgh CPH, Poggenpoel M. exploring the needs and resources of children in a haematology-oncology 
unit. J Interdiscip Health Sci. 2011;16(1):1-12. https://doi.org/ 10.4102/hsag.v16i1.565.

31. Jalmsell L, Kreicbergs U, Onelöv E, Steineck G, Henter J-I. Symptoms affecting children with malignancies during the last month of life: a nationwide follow-up. Pediatrics. 2006;117(4):1314-20.

32. Theunissen JMJ, Hoogerbrugge PM, Van Achterberg T, Prins JB, Vernooij-Dassen MJFJ, Van Den Ende CHM. Symptoms in the palliative phase of children with cancer. Article. Pediatr Blood Cancer. 2007;49(2):160-5. https://doi.org/10.1002/pbc.21042.

33. Anthony S, Dix D, Klaassen R, Scheinemann K, Sung L, Klassen A. Important factors to understanding quality of life according to children with cancer and childhood cancer survivors: PS001. Pediatr Blood Cancer. 2012;59(6).

34. Montoya-Juárez R, García-Caro M, Schmidt-Rio-Valle J, et al. Suffering indicators in terminally ill children from the parental perspective. Eur J Oncol Nurs. 2013;17(6):720-5.

35. Olagunju AT, Sarimiye FO, Olagunju TO, Habeebu MYM, Aina OF. Child's symptom burden and depressive symptoms among caregivers of children with cancers: an argument for early integration of pediatric palliative care. Article. Ann Palliat Med. 2016;5(3):157-65. https://doi.org/10.21037/apm.2016.04.03.

36. Woodgate RL. Feeling states: a new approach to understanding how children and adolescents with cancer experience symptoms. Cancer Nurs. 2008;31(3):229-38.

37. Fan S-Y, Eiser C. Body image of children and adolescents with cancer: a systematic review. Body Image. 2009;6(4):247-56.

38. Abrams AN, Hazen EP, Penson RT. Psychosocial issues in adolescents with cancer. Cancer Treat Rev. 2007;33(7):622-30.

39. Hsiao JL, Evan EE, Zeltzer LK. Parent and child perspectives on physician communication in pediatric palliative care. Palliat Support Care. 2007;5(4):355-65

40. Stegenga K, Ward-Smith P. On receiving the diagnosis of cancer: the adolescent perspective. J Pediatr Oncol Nurs. 2009;26(2):75-80.

41. Jacobs S, Perez J, Cheng YI, Sill A, Wang J, Lyon ME. Adolescent end of life preferences and congruence with their parents' preferences: results of a survey of adolescents with cancer. Pediatr Blood Cancer. 2015;62(4):710-4.

42. Latha SM, Scott JX, Kumar S, Kumar SM, Subramanian L, Rajendran A. Parent's perspectives on the end-of-life care of their child with cancer: Indian perspective. Review. Indian J Palliat Care. 2016;22(3):317-25. https://doi.org/10.4103/09731075.185047.

43. Kamper R, Van Cleve L, Savedra M. Children with advanced cancer: responses to a spiritual quality of life interview. J Spec Pediatr Nurs. 2010;15(4):301-6.

44. Enskär K, Carlsson M, Golsäter M, Hamrin E, Kreuger A. Life situation and problems as reported by children with cancer and their parents. J Pediatr Oncol Nurs. 1997;14(1):18-26.

45. Price J, Jordan J, Prior L, Parkes J. Living through the death of a child: a qualitative study of bereaved parents' experiences. Article. Int J Nurs Stud. 2011;48(11):1384-92. https://doi.org/ 10.1016/j.ijnurstu.2011.05.006.

46. Stevenson M, Achille M, Lugasi T. Pediatric palliative care in Canada and the United States: a qualitative metasummary of the needs of patients and families. J Palliat Med. 2013;16(5):56677. https://doi.org/10.1089/jpm.2011.0076.

47. Monterosso L, Kristjanson LJ, Aoun S, Phillips MB. Supportive and palliative care needs of families of children with lifethreatening illnesses in Western Australia: evidence to guide the development of a palliative care service. Article. Palliat Med. 2007;21(8):689-96. https://doi.org/10.1177/0269216307 083032 .

48. Monterosso L, Kristjanson LJ, Phillips MB. The supportive and palliative care needs of Australian families of children who die from cancer. Article. Palliat Med. 2009;23(6):526-36. https:// doi.org/10.1177/0269216309104060.

49. Boyden JY, Hill DL, Nye RT, et al. Pediatric palliative care parents' distress, financial difficulty, and child symptoms. J Pain Symptom Manag. 2021/08/20/ 2021. https://doi.org/10.1016/j. jpainsymman.2021.08.004

50. Hechler T, Blankenburg M, Friedrichsdorf SJ, et al. Parents' perspective on symptoms, quality of life, characteristics of death and end-of-life decisions for children dying from cancer. Article. Klinische Padiatrie. 2008;220(3):166-74. https://doi.org/10. 1055/s-2008-1065347.

51. Heinze KE, Nolan MT. Parental decision making for children with cancer at the end of life: a meta-ethnography. Article. J Pediatr Oncol Nurs. 2012;29(6):337-45. https://doi.org/10.1177/ 1043454212456905.

52. Wiener L, Tager J, Mack J, Battles H, Bedoya SZ, Gerhardt CA. Helping parents prepare for their child's end of life: a retrospective survey of cancer-bereaved parents. Pediatr Blood Cancer. 2020;67(2):e27993. https://doi.org/10.1002/pbc.27993.

53. Saad R, Kurdahi LB, Yazbick-Dumit N, Irani C, Muwakkit S. Paediatric oncology providers' perspectives on early integration of paediatric palliative care. Review. Int J Palliat Nurs. 2020;26(3):100-9. https://doi.org/10.12968/ijpn.2020.26.3. 100. (A qualitative study exploring perspectives of paediatric oncologists showed that continuous communication between parents, family caregivers and health care providers facilitates integrated care.)

54. Hurley F, Kiernan G, Price J. 'Starting out in haziness': parental experiences surrounding the diagnosis of their child's nonmalignant life-limiting condition in Ireland. Article. J Pediatr Nurs. 2021;59:25-31. https://doi.org/10.1016/j.pedn.2020. 12.015. (A qualitative study exploring perspectives of the parents showed that learning about child's diagnosis was a highly distressing moment for the parents.)

55. Price J, Jordan J, Prior L. A consensus for change: parent and professional perspectives on care for children at the end-oflife. Article. Compr Child Adolesc Nurs. 2013;36(1-2):70-87. https://doi.org/10.3109/01460862.2013.779765.

56. Sailian SD, Salifu Y, Saad R, Preston N. How is dignity understood and preserved in patients with palliative needs in the Middle East? an integrative review. 2021

57. Ciobanu E, Preston N. Hearing the voices of children diagnosed with a life-threatening or life-limiting illness and their parents' accounts in a palliative care setting: a qualitative study. Palliat Med. 2021;35(5):886-92. https://doi.org/10.1177/0269216321 1000238. (This qualitative study in a life-limiting setting involving children and their parents showed that there is often a gap between the child's understanding and experience of illness and parental perception of what child knows. This gap often leads to barriers in communication within families.)

58. Johnston EE, Molina J, Martinez I, et al. Bereaved parents' views on end-of-life care for children with cancer: quality marker implications. Cancer. 2020;126(14):3352-9. https://doi.org/10. 1002/cncr.32935.

59. Pritchard M, Srivastava DK, Okuma JO, et al. Bereaved parents' perceptions about when their child's cancer-related death would occur. Article. J Pain Symptom Manag. 2009;38(4):561-7. https://doi.org/10.1016/j.jpainsymman.2009.01.005.

60. Kars MC, Grypdonck MHF, De Korte-Verhoef MC, et al. Parental experience at the end-of-life in children with cancer: Preservation' and "letting go" in relation to loss. Article. Support Care Cancer. 2011;19(1):27-35. https://doi.org/10.1007/ s00520-009-0785-1.

61. Wang SC, Wu LM, Yang YM, Sheen JM. The experience of parents living with a child with cancer at the end of life Article. 
Eur J Cancer Care. 2019;28(4):e13061. https://doi.org/10.1111/ ecc. 13061.

62. Kenny M, Darcy-Bewick S, Martin A, et al. You are at rock bottom: a qualitative systematic review of the needs of bereaved parents as they journey through the death of their child to cancer. Review. J Psychosoc Oncol. 2020. https://doi.org/10.1080/07347 332.2020.1762822.

63. Das K, Khanna T, Arora A, Agrawal N. Parents' acceptance and regret about end of life care for children who died due to malignancy. Article. Support Care Cancer. 2020;28(1):303-8. https://doi.org/10.1007/s00520-019-04806-0.

64. McCarthy MC, Clarke NE, Ting CL, Conroy R, Anderson VA, Heath JA. Prevalence and predictors of parental grief and depression after the death of a child from cancer. Article. J Palliat Med. 2010;13(11):1321-6. https://doi.org/10.1089/jpm.2010.0037.

65. Surkan PJ, Kreicbergs U, Valdimarsdóttir U, et al. Perceptions of inadequate health care and feelings of guilt in parents after the death of a child to a malignancy: a population-based long-term follow-up. Article. J Palliat Med. 2006;9(2):317-31. https://doi. org/10.1089/jpm.2006.9.317.

66. Wikman A, Mattsson E, von Essen L, Hovén E. Prevalence and predictors of symptoms of anxiety and depression, and comorbid symptoms of distress in parents of childhood cancer survivors and bereaved parents five years after end of treatment or a child's death. Article. Acta Oncol. 2018;57(7):950-7. https://doi.org/10. 1080/0284186X.2018.1445286.

67. Price JE, Jones AM. Living through the life-altering loss of a child: a narrative review. Acta. Compr Child Adolesc Nurs. 2015;38(3):222-40. https://doi.org/10.3109/01460862.2015. 1045102.

68. Das MK, Arora NK, Gaikwad H, et al. Grief reaction and psychosocial impacts of child death and stillbirth on bereaved North Indian parents: a qualitative study. PLoS ONE. 2021;16(1):e0240270-e0240270. https://doi.org/10.1371/journ al.pone. 0240270 .

69. Fraser LK, Miller M, McKinney PA, Parslow RC, Feltbower RG. Referral to a specialist paediatric palliative care service in oncology patients. Pediatr Blood Cancer. 2011;56(4):677-80. https://doi.org/10.1002/pbc.22667.

70. Johnston DL, Vadeboncoeur C. Palliative care consultation in pediatric oncology. Support Care Cancer. 2012;20(4):799-803. https://doi.org/10.1007/s00520-011-1152-6.

71. Levine DR, Johnson LM, Snyder A, et al. Integrating palliative care in pediatric oncology: evidence for an evolving paradigm for comprehensive cancer care. Article. JNCCN J Natl Compr Cancer Netw. 2016;14(6):741-8. https://doi.org/10.6004/jnccn. 2016.0076.

72. Menon BS, Mohamed M, Juraida E, Ibrahim H. Pediatric cancer deaths: curative or palliative? J Palliat Med. 2008;11(10):13013. https://doi.org/10.1089/jpm.2008.0167.

73. Tzuh Tang S, Hung YN, Liu TW, et al. Pediatric end-of-life care for Taiwanese children who died as a result of cancer from 2001 through 2006. J Clin Oncol. 2011;29(7):890-4. https://doi.org/ 10.1200/jco.2010.32.5639.

74. Ullrich CK, Lehmann L, London WB, et al. End-of-life care patterns associated with pediatric palliative care among children who underwent hematopoietic stem cell transplant. Article. Biol Blood Marrow Transplant. 2016;22(6):1049-55. https://doi.org/ 10.1016/j.bbmt.2016.02.012.

75. Vern-Gross TZ, Lam CG, Graff Z, et al. Patterns of end-oflife care in children with advanced solid tumor malignancies enrolled on a palliative care service. Article. J Pain Symptom Manag. 2015;50(3):305-12. https://doi.org/10.1016/j.jpainsymman.2015.03.008.
76. Feudtner C, Kang TI, Hexem KR, et al. Pediatric palliative care patients: a prospective multicenter cohort study. Pediatrics. 2011;127(6):1094-101.

77. Jordan RI, Allsop MJ, ElMokhallalati Y, et al. Duration of palliative care before death in international routine practice: a systematic review and meta-analysis Article. BMC Medicine. 2020;18(1):368. https://doi.org/10.1186/s12916-020-01829-x. ()

78. Bradshaw G, Hinds PS, Lensing S, Gattuso JS, Razzouk BI. Cancer-related deaths in children and adolescents. J Palliat Med. 2005;8(1):86-95. https://doi.org/10.1089/jpm.2005.8.86.

79. Howell DA, Shellens R, Roman E, Garry AC, Patmore R, Howard MR. Haematological malignancy: are patients appropriately referred for specialist palliative and hospice care? A systematic review and meta-analysis of published data. Palliat Med. 2011;25(6):630-41. https://doi.org/10.1177/0269216310391692.

80. Rost M, Acheson E, Kühne T, et al. Palliative care in Swiss pediatric oncology settings: a retrospective analysis of medical records. Article. Support Care Cancer. 2018;26(8):2707-15. https://doi.org/10.1007/s00520-018-4100-x.

81. Vallero SG, Lijoi S, Bertin D, et al. End-of-life care in pediatric neuro-oncology. Pediatr Blood Cancer. 2014;61(11):2004-11. https://doi.org/10.1002/pbc.25160.

82. Labudde EJ, DeGroote NP, Smith S, et al. Evaluating palliative opportunities in pediatric patients with leukemia and lymphoma. Cancer Med. 2021/04/01 2021;10(8):2714-2722. https://doi.org/10.1002/cam4.3862. (This survey study explored opportunities or events where palliative care integration in haematological malignancies was feasible. The study results showed that significant number of opportunities for palliative care integration was missed in haematological malignancies especially in end of life care setting.)

83. De Graves S, Aranda S. Exploring documentation of endof-life care of children with cancer. Int J Palliat Nurs. 2002;8(9):435-43.

84.•• (This qualitative content analysis in a mixed group of health professionals in USA showed that poor prognosis, uncontrolled symptoms, comorbidities and psychosocial needs were the common triggers for palliative care referral.)

85.• Lockwood BJ, Ntukidem OL, Ehrman SE, et al. Palliative care referral patterns for adolescent and young adult patients at a comprehensive cancer center. J Adolesc Young Adult Oncol. 2021/02/01 2020;10(1):109-114. https://doi.org/10.1089/jayao. 2020.0081. (This audit conducted in a cancer centre in USA showed that among adolescents and young adults only $8.4 \%$ of them were referred to palliative care, and high symptom burden and perception of poor survival triggered a referral.)

86.•• Mitchell S, Slowther A-M, Coad J, Bertaud S, Dale J. Facilitators and barriers to the delivery of palliative care to children with life-limiting and life-threatening conditions: a qualitative study of the experiences and perceptions of healthcare professionals. Arch Dis Child. 2021:archdischild-2021-321808. https://doi. org/10.1136/archdischild-2021-321808. (This qualitative study conducted among paediatric health care professionals at the four regions of United Kingdom showed that uncertainity and avoiding conversations about death and dying were the major barriers for integration.)

87. Fowler K, Poehling K, Billheimer D, et al. Hospice referral practices for children with cancer: a survey of pediatric oncologists. Article. J Clin Oncol. 2006;24(7):1099-104. https://doi.org/10. 1200/JCO.2005.02.6591.

88. Ananth P, Monsereenusorn C, Ma C, Al-Sayegh H, Wolfe J, Rodriguez-Galindo $\mathrm{C}$. Influence of early phase clinical trial enrollment on patterns of end-of-life care for children with advanced 
cancer. Article. Pediatr Blood Cancer. 2018;65(1):e26748. https://doi.org/10.1002/pbc.26748.

89. Levine DR, Johnson L-M, Mandrell B, et al. Does phase I trial enrollment preclude quality end of life care?: Phase I Trial Enrollment and End of Life Care Characteristics in Children with Cancer. Cancer. 2015;121(9):1508-12. https://doi.org/10. 1002/cncr.29230.

90. - Arias-Casais N, Garralda E, Pons JJ, Marston J, Chambers L, Downing J, Ling J, Rhee JY, de Lima L, Centeno C. Mapping pediatric palliative care development in the WHOEuropean region: children living in low-to-middle-income countries are less likely to access it. Article. J Pain Symptom Manag. 2020;60(4):746-53. https://doi.org/10.1016/j.jpainsymman.2020.04.028. (A survey conducted by the European Association of Palliative Care (EAPC) showed that children with cancer in low middle income countries within Europe are less likely to access palliative care due to limited awareness about palliative care among public and health care providers.)

91. Ghoshal A, Salins N, Damani A, Deodhar J, Muckaden M. Specialist pediatric palliative care referral practices in pediatric oncology: a large 5-year retrospective audit. Original Article. Indian J Palliat Care. 2016;22(3):266-73. https://doi.org/10. 4103/0973-1075.185031.

92. Jacob J, Matharu JK, Palat G, et al. End-of-life treatments in pediatric patients at a government tertiary cancer center in India. Article. J Palliat Med. 2018;21(7):907-12. https://doi.org/10. 1089/jpm.2017.0632.

93. Adusumilli P, Nayak L, Viswanath V, Digumarti L, Digumarti RR. Palliative care and end-of-life measure outcomes: experience of a tertiary care institute from South India. South Asian J Cancer. 2018;7(3):210-3. https://doi.org/10.4103/sajc.sajc_257_17.

94. Atreya S. Referral patterns of gynecological cancer patients to a palliative medicine unit: a 2 years retrospective analysis. Indian J Palliat Care. 2017;23(4):409-12. https://doi.org/10. 4103/ijpc.Ijpc_77_17.

95. Chatterjee A, Nimje G, Jain PN. Referral pattern to a tertiary care cancer pain clinic in India. J Pain Palliat Care Pharmacother. 2019;33(1-2):6-14. https://doi.org/10.1080/15360288. 2019.1631240

96. Sharma K, Mohanti BK, Rath GK, Bhatnagar S. Pattern of palliative care, pain management and referral trends in patients receiving radiotherapy at a tertiary cancer center. Indian J Palliat Care. 2009;15(2):148-54. https://doi.org/10.4103/09731075.58462.

97. Sinha S, Matharu JK, Jacob J, et al. Cancer treatment and endof-life care. J Palliat Med. 2018;21(8):1100-6. https://doi.org/ 10.1089/jpm.2017.0695.

98. Chong L, Khalid F. Paediatric palliative care in Malaysia: survey of knowledge base and barriers to referral. Article. Prog Palliat Care. 2014;22(4):195-200. https://doi.org/10.1179/ 1743291X13Y.0000000074.

99. Eke GK, Akani NA. Outcome of childhood malignancies at the university of port Harcourt teaching hospital: a call for implementation of palliative care. Article. African Health Sci. 2016;16(1):75-82. https://doi.org/10.4314/ahs.v16i1.10.

100. Ziani A, El Kababri M, El Khorassani M, Kili A, Khattab $\mathrm{M}$, Hessissen L. Needs of children during palliative care in pediatric oncology - a parents' survey in Morocco. Article. Psycho-Oncologie. 2015;9(3):179-84. https://doi.org/10.1007/ s11839-015-0530-6.

101. Delgado E, Barfield RC, Baker JN, et al. Availability of palliative care services for children with cancer in economically diverse regions of the world. Article. Eur J Cancer. 2010;46(12):2260-6. https://doi.org/10.1016/j.ejca.2010.05. 006
102.• Mitchell S, Harding S, Samani M, Slowther A-M, Coad J, Dale J. Experiences of general practice of children with complex and palliative care needs and their families: a qualitative study. BMJ Open. 2021;11(1):e041476. https://doi.org/10.1136/bmjopen2020-041476. (This qualitative study conducted in United Kingdom explored challenges of children and their families with complex palliative care needs. The findings of the study showed gaps in palliative care provision in general practice setting and a need for a palliative care capacity building.)

103.• Laronne A, Granek L, Wiener L, Feder-Bubis P, Golan H. Organizational and individual barriers and facilitators to the integration of pediatric palliative care for children: a grounded theory study. Palliat Med. 2021;35(8):1612-24. https://doi.org/ $10.1177 / 02692163211026171$. (This qualitative grounded theory study conducted in Israel in a mixed group of healthcare professionals explored barriers for palliative care integration in paediatric oncology. Lack of resources were organisational barriers. Attitudes, emotions and personalities of the healthcare providers were the individual barriers.)

104. Chong PH, Hamsah E, Goh C. Paediatric palliative care in the Asia Pacific region: where are we now?. Article. BMJ Support Palliat Care. 2017;7(1):17-22. https://doi.org/10.1136/bmjsp care-2014-000812.

105. Downing J, Marston J, Muckaden MA, et al. Transforming children's palliative care - from ideas to action: highlights from the first ICPCN conference on children's palliative care. Conference Paper. Ecancermedicalscience. 2014;8(1):415. https://doi.org/10. 3332/ecancer.2014.415.

106. Ghoshal A, Talawadekar P, Palleri A, Marston J, Muckaden M. Impact of educational training in improving skills, practice, attitude, and knowledge of healthcare workers in pediatric palliative care: children's palliative care project in the Indian state of Maharashtra. Article. Indian J Palliat Care. 2018;24(4):411-25. https://doi.org/10.4103/IJPC.IJPC_43_18.

107. Downing J, Powell RA, Marston J, et al. Children's palliative care in low- and middle-income countries. Review. Arch Dis Child. 2016;101(1):85-90. https://doi.org/10.1136/archdischi ld-2015-308307.

108. Song IG, Kwon SY, Chang YJ, et al. Paediatric palliative screening scale as a useful tool for clinicians' assessment of palliative care needs of pediatric patients: a retrospective cohort study. BMC Palliative Care. 2021/05/24 2021;20(1):73. https://doi.org/ 10.1186/s12904-021-00765-8

109. Coombes LH, Wiseman T, Lucas G, Sangha A, Murtagh FEM. Health-related quality-of-life outcome measures in paediatric palliative care: a systematic review of psychometric properties and feasibility of use. Review. Palliat Med. 2016;30(10):935-49. https://doi.org/10.1177/0269216316649155.

110. Tomlinson D, Bartels U, Hendershot E, Maloney AM, Ethier MC, Sung L. Factors affecting treatment choices in paediatric palliative care: comparing parents and health professionals. Article. Eur J Cancer. 2011;47(14):2182-7. https://doi.org/10.1016/j. ejca.2011.04.038.

111. Gans D, Kominski GF, Roby DH, et al. Better outcomes, lower costs: palliative care program reduces stress, costs of care for children with life-threatening conditions. Article. Policy brief (UCLA Center for Health Policy Research). 2012;(PB2012-3):1-8.

112. Mitchell S, Morris A, Bennett K, Sajid L, Dale J. Specialist paediatric palliative care services: what are the benefits?. Article. Arch Dis Child. 2017;102(10):923-9. https://doi.org/10.1136/ archdischild-2016-312026.

113. Weaver MS, Rosenberg AR, Tager J, Wichman CS, Wiener L. A summary of pediatric palliative care team structure and services as reported by centers caring for children with cancer. Article. 
J Palliat Med. 2018;21(4):452-62. https://doi.org/10.1089/jpm. 2017.0405

114. Zernikow B, Szybalski K, Hübner-Möhler B, et al. Specialized pediatric palliative care services for children dying from cancer: a repeated cohort study on the developments of symptom management and quality of care over a 10-year period. Article. Palliat Med. 2019;33(3):381-91. https://doi.org/10.1177/02692 16318818022.

115. Osenga K, Postier A, Dreyfus J, Foster L, Teeple W, Friedrichsdorf SJ. A comparison of circumstances at the end of life in a aospital setting for children with palliative care involvement versus those without. Article. J Pain Symptom Manag. 2016;52(5):673-80. https://doi.org/10.1016/j.jpainsymman. 2016.05.024

116. Zhukovsky DS, Herzog CE, Kaur G, Palmer JL, Bruera E. The impact of palliative care consultation on symptom assessment, communication needs, and palliative interventions in pediatric patients with cancer. Article. J Palliat Med. 2009;12(4):343-9. https://doi.org/10.1089/jpm.2008.0152.

117. Balkin EM, Thompson D, Colson KE, Lam CG, Matthay KK. Physician perspectives on palliative care for children with neuroblastoma: an international context. Article. Pediatr Blood Cancer. 2016;63(5):872-9. https://doi.org/10.1002/pbc.25900.

118. Doherty M, Power L, Thabet C. Delivering hospital-based pediatric palliative care: the symptoms, interventions, and outcomes for children with cancer in Bangladesh. Article. JCO Glob Oncol. 2020;6:884-91. https://doi.org/10.1200/GO.20. 00076.

119. Kuhlen M, Schlote A, Borkhardt A, Janen G. Palliative home care of children: an opinion survey of orphaned parents. Article. Klin Padiatr. 2014;226(3):182-7. https://doi.org/10.1055/s0034-1371841.

120. Lindley LC, Keim-Malpass J. Quality of paediatric hospice care for children with and without multiple complex chronic conditions. Review. Int J Palliat Nurs. 2017;23(5):230-7. https://doi. org/10.12968/ijpn.2017.23.5.230.

121. Schmidt P, Otto M, Hechler T, Metzing S, Wolfe J, Zernikow B. Did increased availability of pediatric palliative care lead to improved palliative care outcomes in children with cancer? J Palliat Med. 2013;16(9):1034-9.

122. Kaye EC, Weaver MS, DeWitt LH, et al. The impact of specialty palliative care in pediatric oncology: a systematic review. J Pain Symptom Manage. 2020. https://doi.org/10.1016/j.jpainsymman. 2020.12.003

123. Marcus KL, Santos G, Ciapponi A, et al. Impact of specialized pediatric palliative care: a systematic review. J Pain Symptom Manage. 2020;59(2):339-364.e10. https://doi.org/10.1016/j.jpain symman.2019.08.005.

124. Friedrichsdorf SJ, Postier A, Dreyfus J, Osenga K, Sencer S, Wolfe J. Improved quality of life at end of life related to homebased palliative care in children with cancer. Article. J Palliat Med. 2015;18(2):143-50. https://doi.org/10.1089/jpm.2014. 0285 .

125. Hendricks-Ferguson VL, Haase JE. Parent perspectives of receiving early information about palliative and end-of-life care options from their child's pediatric providers. Review. Cancer Nurs. 2019;42(4):E22-30. https://doi.org/10.1097/NCC.00000 00000000589.

126. Niswander LM, Cromwell P, Chirico J, Gupton A, Korones DN. End-of-life care for children enrolled in a communitybased pediatric palliative care program. Article. J Palliat Med. 2014;17(5):589-91. https://doi.org/10.1089/jpm.2013.0576.

127. Plaza Fornieles M, García-Marcos Barbero P, Galera Miñarro AM, et al. [Efficacy of the paediatrics palliative care team of Murcia according to the experience of the parents]. An Pediatr (Barc). 2020;93(1):4-15. Eficacia del Equipo de Cuidados
Paliativos Pediátricos de Murcia según la experiencia de los padres. https://doi.org/10.1016/j.anpedi.2019.07.001

128. Ekberg S, Danby S, Herbert A, Bradford NK, Yates P. Affording opportunities to discuss deterioration in paediatric palliative care consultations: a conversation analytic study Article. BMJ Support Palliat Care. 2020;10(2):e13. https://doi.org/10.1136/ bmjspcare-2016-001130.

129. Ekberg S, Danby S, Rendle-Short J, Herbert A, Bradford NK, Yates P. Discussing death: making end of life implicit or explicit in paediatric palliative care consultations. Patient Educ Couns. 2019;102(2):198-206.

130. Kassam A, Skiadaresis J, Alexander S, Wolfe J. Differences in end-of-life communication for children with advanced cancer who were referred to a palliative care team. Article. Pediatr Blood Cancer. 2015;62(8):1409-13. https://doi.org/10.1002/ pbc. 25530 .

131. Mesukko J, Turale S, Jintrawet U, Niyomkar S. Palliative care guidelines for physicians and nurses caring for children and their families in the pediatric intensive care units: a participatory action research study. Article. Pac Rim Int J Nurs Res. 2020;24(2):202-18.

132. Seddighzadeh RP, Lawrence K, Hamby T, Hoeft A. Influence of palliative care on medical treatment of pediatric patients with complex chronic diseases at cook children's medical center. Article. J Palliat Med. 2018;21(11):1617-20. https://doi.org/ 10.1089/jpm.2018.0079.

133. Greenfield K, Holley S, Schoth DE, et al. A mixed-methods systematic review and meta-analysis of barriers and facilitators to paediatric symptom management at end of life. Review. Palliat Med. 2020;34(6):689-707. https://doi.org/10.1177/02692 16320907065

134. Atout M, Hemingway P, Seymour J. The experience of decision making in the care of children with palliative care needs: the experiences of Jordanian Mothers. Article. Compr Child Adolesc Nurs. 2017;40(4):240-56. https://doi.org/10.1080/ 24694193.2017.1330371.

135. Dreesens D, Veul L, Westermann J, et al. The clinical practice guideline palliative care for children and other strategies to enhance shared decision-making in pediatric palliative care; pediatricians' critical reflections. Article. BMC Pediatr. 2019;19(1):467. https://doi.org/10.1186/s12887-019-1849-0.

136. Brock KE, Steineck A, Twist CJ. Trends in end-of-life care in pediatric hematology, oncology, and stem cell transplant patients. Article. Pediatr Blood Cancer. 2016;63(3):516-22. https://doi.org/10.1002/pbc.25822.

137. Charlebois J, Cyr C. Quality indicators for paediatric palliative care. Article. Paediatr Child Health (Canada). 2015;20(3):145-7. https://doi.org/10.1093/pch/20.3.145.

138. Mitchell S, Dale J. Advance care planning in palliative care: Aaqualitative investigation into the perspective of paediatric intensive care unit staff. Article. Palliat Med. 2015;29(4):3719. https://doi.org/10.1177/0269216315573000.

139. Chong PH, De Castro Molina JA, Teo K, Tan WS. Paediatric palliative care improves patient outcomes and reduces healthcare costs: evaluation of a home-based program. Article. BMC Palliat Care. 2018;17(1):11. https://doi.org/10.1186/ s12904-017-0267-z.

140. Taylor J, Booth A, Beresford B, Phillips B, Wright K, Fraser L. Specialist paediatric palliative care for children and young people with cancer: a mixed-methods systematic review. Revie. Palliat Med. 2020;34(6):731-75. https://doi.org/10. 1177/0269216320908490.

141. Fraser LK, Van Laar M, Miller M, et al. Does referral to specialist paediatric palliative care services reduce hospital admissions in oncology patients at the end of life. Article. $\mathrm{Br}$ 
J Cancer. 2013;108(6):1273-9. https://doi.org/10.1038/bjc. 2013.89.

142. Keele L, Keenan HT, Sheetz J, Bratton SL. Differences in characteristics of dying children who receive and do not receive palliative care. Article. Pediatrics. 2013;132(1):72-8. https:// doi.org/10.1542/peds.2013-0470.

143. Kim CH, Song IG, Kim MS, Lee JY, Lim NG, Shin HY. Healthcare utilization among children and young people with life-limiting conditions: exploring palliative care needs using National Health Insurance claims data Article. Sci Rep. 2020;10(1):2692. https://doi.org/10.1038/ s41598-020-59499-x.

144. Lin SC, Huang MC, Yasmara D, Wuu HL. Impact of palliative care on end-of-life care and place of death in children, adolescents, and young adults with life-limiting conditions: a systematic review. Review. Palliat Support Care. 2021. https://doi.org/ 10.1017/S1478951520001455.

145. Price J, McCloskey S, Brazil K. The role of hospice in the transition from hospital to home for technology-dependent childrena qualitative study. Article. J Clin Nurs. 2018;27(1-2):396-406. https://doi.org/10.1111/jocn.13941.

146. Inglin S, Hornung R, Bergstraesser E. Palliative care for children and adolescents in Switzerland: a needs analysis across three diagnostic groups. Article. Eur J Pediatr. 2011;170(8):1031-8. https://doi.org/10.1007/s00431-011-1398-5.

147. Verberne LM, Schouten-van Meeteren AYN, Bosman DK, et al. Parental experiences with a paediatric palliative care team: a qualitative study. Article. Palliat Med. 2017;31(10):956-63. https://doi.org/10.1177/0269216317692682.

148. Cheng BT, Wangmo T. Palliative care utilization in hospitalized children with cancer. Article. Pediatr Blood Cancer. 2020;67(1):e28013. https://doi.org/10.1002/pbc.28013.

149. Kaye E, Friebert S, Baker J. Early integration of palliative care for children with high risk cancer and their families. Pediatr Blood Cancer. 2016;63(4):593-7.

150. Baker JN, Hinds PS, Spunt SL, et al. Integration of palliative care practices into the ongoing care of children with cancer: individualized care planning and coordination. Pediatr Clin North Am. 2008;55(1):223-50. xii. https://doi.org/10.1016/j.pcl.2007. 10.011 .

151. Duncan J, Spengler E, Wolfe J. Providing pediatric palliative care: PACT in action. MCN Am J Matern Child Nurs. 2007;32(5):279-87. https://doi.org/10.1097/01.NMC.00002 87997.97931.5f

152. Golan H, Bielorai B, Grebler D, Izraeli S, Rechavi G, Toren A. Integration of a palliative and terminal care center into a comprehensive pediatric oncology department. Pediatr Blood Cancer. 2008;50(5):949-55. https://doi.org/10.1002/pbc.21476.

153. Harper J, Hinds PS, Baker JN, Hicks J, Spunt SL, Razzouk BI. Creating a palliative and end-of-life program in a cure-oriented pediatric setting: the zig-zag method. J Pediatr Oncol Nurs. 2007;24(5):246-54. https://doi.org/10.1177/1043454207303882.

154. Toce $S$, Collins MA. The FOOTPRINTS model of pediatric palliative care. J Palliat Med. 2003;6(6):989-1000. https://doi.org/ 10.1089/109662103322654910.

155. Brock KE, Snaman JM, Kaye EC, et al. Models of pediatric palliative oncology outpatient care-benefits, challenges, and opportunities. Review. J Oncol Pract. 2019;15(9):476-87. https://doi. org/10.1200/JOP.19.00100. (This narrative review describes five palliative care models in paediatric oncology practiced in various hospitals of the United States.)

156. Brock KE, Allen KE, Falk E, et al. Association of a pediatric palliative oncology clinic on palliative care access, timing and location of care for children with cancer. Article. Support Care Cancer. 2021;29(4):1849-57. https://doi.org/10.1007/s00520020-05671-y. (This study demonstrated that embedded model of integrated paediatric palliative care in oncology was associated with better acceptance of paediatric palliative care and child was able to spend more time at home.)

157. Farooki S, Olaiya O, Tarbell L, et al. A quality improvement project to increase palliative care team involvement in pediatric oncology patients Article. Pediatr Blood Cancer. 2021;68(2):e28804. https://doi.org/10.1002/pbc.28804. (This study showed that interventions leaning towards embedding in paediatric palliative oncology setting increased the time interval between paediatric palliative care consult and death.•)

158. Falk EE, Allen KE, DeGroote NP, Wasilewski-Masker K, Brock KE. Feasibility, acceptability, and education of pediatric oncology providers before and after an embedded pediatric palliative oncology clinic. JCO Oncol Pract. 2021;17(6):e714-29. https:// doi.org/10.1200/op.20.00881. (This study showed thar embedded model of palliative care in paediatric oncology improved feasiblity and acceptance of palliative care and palliative care education.)

159. Pennarola B, MacDonell-Yilmaz RE, Sprinz P, Renaud T. Impact of a pediatric palliative care team on resident education in end of life care. Prog Palliat Care. 2021/07/04 2021;29(4): 217-222. https://doi.org/10.1080/09699260.2021.1871578

160. Podda M, Schiavello E, Visconti G, et al. Customised pediatric palliative care: Integrating oncological and palliative care priorities. Article. Acta Paediatr Int J Paediatr. 2021;110(2):682-8. https://doi.org/10.1111/apa.15415.

Publisher's Note Springer Nature remains neutral with regard to jurisdictional claims in published maps and institutional affiliations. 